\title{
A EXPERIÊNCIA DAS CLASSES-PILOTO ORGANIZADAS PELO GEEMPA, AO TEMPO DA MATEMÁTICA MODERNA
}

\section{The Experience of Pilot Classes Organised by GEEMPA in The Modern Mathematics Times}

Maria Cecília Bueno Fischer ${ }^{1}$

\section{Resumo}

O texto aborda o estudo, em desenvolvimento, da experiência realizada nas classes-piloto, organizadas pelo Grupo de Estudos sobre o Ensino da Matemática de Porto Alegre - GEEMPA, em 1972. O estudo investiga a experiência realizada nessas classes e, por meio de procedimentos envolvendo documentos orais e escritos, procura analisar as práticas desenvolvidas que, segundo se sabe, marcaram a história da Educação Matemática nas escolas de Porto Alegre. Este estudo integra a pesquisa que busca traços dos cotidianos escolares deixados por professores, durante um tempo que correspondia a um movimento intemacional de renovação do ensino da matemática. A metodologia da pesquisa transita entre a pesquisa documental e a história oral, dado que as fontes são professoras das classes e os arquivos do GEEMPA, onde se encontram documentos relativos ao planejamento e desenvolvimento de tais classes, entre outros. Até o momento, pelos depoimentos das professoras, pode-se verificar que a experiência representou uma importante contribuição, tanto na formação docente como na dos alunos das classes. A investigação busca responder a algumas questões: como a escola acolhia a experiência, realizada numa de suas classes? Como era a relação com as demais turmas da mesma série? Foi possível socializar os resultados da experiência com outras turmas e escolas de Porto Alegre ou do Estado? Como é que se desenvolveu uma experiência tão positiva - numa análise preliminar - quando o Movimento da Matemática Moderna já dava sinais de fracasso mundialmente?

Palavras-chave: Matemática Moderna; História da Educação Matemática; formação de professores.

1 Doutora em Educação. Integrante do Grupo de Pesquisa de História da Educação Matemática - GHEMAT. Professora do Curso de Licenciatura em Matemática na Universidade do Vale do Rio dos Sinos - UNISINOS, São Leopoldo/RS - ceciliabfischer@terra.com.br. 


\section{Abstract}

The subject of this text is the study of an experience realized in pilot-classes, implemented by GEEMPA - Study Group on teaching Maths of Porto Alegre, in 1972. As it is well known, this particular GEEMPA's experience made history in terms of Maths in Porto Alegre schools. The main objective of this study is to analyse this particular experience. It is part of a wider research that aims to teachers' traces left in a time of international renew on maths teaching methods. The research methodology combine oral history collected through interviews undertaken with teachers of pilot-classes and, also, analysis of documents of GEEMPA's archives where one can find didatic materials related to planning and development of those classes and other documents. Up to now, taken the information given by the interviewers, one can identify that the pilot-classes experience was very important in the processes of teaching teachers as well as for the pupils. The main questions of the research project are: how the school as a whole integrated the pilot experience developed in just one of its classes? How was the relationship with other classes of the same school level? Was it possible socialise the results of the experience with colleagues of other classes and schools of Porto Alegre and in the state of Rio Grande do Sul as a whole? How it can be explained that this experience was, as itseems, very positive, when the Modem Mathematics Movement in a world-wile level was, by that time, declining?

Keywords: Modern Mathematics; Mathematics Education History; teaching teachers.

\section{Uma introdução}

O estudo que estou desenvolvendo propõe-se a investigar a experiência com classes-piloto, realizadas sob a organização do Grupo de Estudos sobre o Ensino da Matemática de Porto Alegre - GEEMPA, ao tempo do Movimento da Matemática Moderna (MMM). Este estudo integra a pesquisa sobre a Matemática Moderna em Porto Alegre, que busca traços de cotidianos escolares deixados nas práticas dos professores ao tempo desse movimento internacional de renovação do ensino da matemática. Pretendo apresentar, no texto, alguns indícios acerca da experiência, apontados pelas entrevistas realizadas com algumas professoras que atuaram nas classes-piloto, bem como pelos documentos a que tive acesso no acervo do GEEMPA, arriscando-me a proceder como historiadora, seara de pesquisa na qual me inicio. Apóio-me nos textos e registros, que constituo como fontes, "como traços portadores de significado" para resolver os problemas que me são colocados a resolver, procurando ir além do que é dito, ver além do que é mostrado, conforme sugere Pesavento (2005, p. 65). 


\section{Situando o Grupo de Estudos de Porto Alegre}

Nos anos 1970, em Porto Alegre, no Rio Grande do Sul, quando o Movimento da Matemática Moderna (MMM) ainda se fazia presente no Brasil, um Grupo que teve destaque e uma participação intensa junto aos professores foi o GEEMPA, Grupo de Estudos sobre o Ensino de Matemática de Porto Alegre. O Grupo foi fundado "numa época em que a influência da matemática moderna já penetrava nos livros didáticos e já era tema de debate público" (BÜRIGO, 1989, p. 138).

Na sua fundação, em setembro de 1970, o GEEMPA reuniu profissionais decididos a investir em pesquisas e ações voltadas para a melhoria do ensino da Matemática e foi assim que atuou até meados de 1983, quando ampliou seus objetivos estatutários. Dedica-se, a partir desse momento, à pesquisa na área da educação e, mesmo mantendo a sigla, passa a denominar-se Grupo de Estudos sobre Educação, Metodologia de Pesquisa e Ação, não mais mantendo seu foco de ação no ensino e na aprendizagem da matemática, sem, todavia, abandoná-los.

Conforme as palavras da professora Ana Maria Carvalho da Rocha, que foi presidente do Grupo,

a época era fecunda. A fundação do GEEMPA sofria a inspiração do movimento cultural de fins dos anos 60, que eclodiu no âmbito da política educacional mundial, em maio de 1968, na França. A influência do movimento internacional na área da Educação se fez, assim, presente no ato de fundação do GEEMPA. Um movimento de contestação no âmbito das práticas culturais e educacionais que repercutiu num movimento intemacional de renovação do ensino da matemática, conhecido como "Matemática Modema" (ROCHA, 2000).

Os fundadores do Grupo, na sua maionia professoras primánias, atuavam no Instituto de Educação General Flores da Cunha, de Porto Alegre, local onde se realizou a assembléia de fundação do GEEMPA, e já apresentavam, na época, uma trajetória profissional com participação efetiva no Movimento da Matemática Modema, o que se refletiu nos trabalhos produzidos pelo Grupo, especialmente em sua primeira década de existência. Em 1966, antes mesmo da fundação do GEEMPA, foi iniciado um curso de formação de professores de 'matemática modema' no Instituto de Educação, "uma escola com um trabalho já desenvolvido em termos de experiências de renovação do ensino da matemática" (BÜRIGO, 1989, p. 138). Quem coordenou o curso, envolvendo professores do primário e do secundário, foi a professora Esther Grossi, que veio a se destacar como uma das figuras de maior influência no GEEMPA, em toda a sua trajetónia, até os dias de hoje²

2 A professora Esther Pillar Grossi é a atual presidente do GEEMPA. 
A professora Esther, uma das fundadoras, primeira presidente e atuante pesquisadora do Grupo, confirma a participação do GEEMPA no Movimento da Matemática Moderna, que tinha como foco, segundo ela, a reestruturação da Matemática como ciência. Pode-se caracterizar este período, conforme a professora, como um tempo de "depuração dos livros-texto de mil incorreções matemáticas, ao mesmo tempo em que bons matemáticos passaram a se ocupar do ensino, criando atividades didáticas logicamente condizentes com os conteúdos visados, o que foi um avanço extraordinário" (GROSSI, 1994, p. 97). Ressalta a professora Esther, no entanto, que este período representava um nível da caminhada da didática da Matemática "marcado por uma incompletude que era o desconhecimento do processo de aprendizagem do aluno" (GROSSI, 1994, p. 97).

A professora Esther volta a manifestar-se, nesse sentido, muitos anos depois, na publicação em homenagem aos 35 anos do GEEMPA, completados em setembro de 2005. Ela tece algumas críticas ao trabalho de Dienes, novamente referindo-se à questão da aprendizagem. Diz ela: "o conjunto de atividades criadas por Dienes em vários domínios matemáticos consistia em fazer os alunos jogar, a fim de resolver problemas instigadores, mas, a bem dizer, apareciam conteúdos matemáticos e não o processo de aprendizagem dos alunos" (2005, p. 14).

Ainda segundo a professora, naquela época ela se "colocava dentro do movimento da Matemática Modema". E continua: "meu primeiro contato com ele [o MMM] foi por meio de Lucienne Felix e, depois, com os blocos lógicos e as publicações de Zoltan Dienes, da mesma maneira que através dos livros de George Pappy" (GROSSI, 2005, p. 12).

Em 1971, conforme destaca, o GEEMPA estabeleceu um contrato com Dienes para a realização de trabalhos em conjunto em Porto Alegre, que se desenrolaram durante vários anos. Além de Dienes, outros também se ligaram ao GEEMPA, como Tamás Varga, Maurice Glaymann e Claude Gaulin (GROSSI, 2005).

refere:

Ainda sobre o trabalho de Dienes, a professora Esther assim se

Dienes criava atividades relativas a aspectos importantes da matemática, fora dos programas oficiais, mas, o que era surpreendente na sua visão, era a capacidade de utilizar complexas estruturas matemáticas com alunos muito jovens e obter um grau muito grande de resultados positivos, o que colocava os professores numa posição pouco confortável ao ver as boas performances dos alunos frente às suas dificuldades em sequer acompanhá-los (2005, p. 13).

Ao mesmo tempo, considera ela, "Dienes repetia a maneira convencional de desenvolver a aprendizagem da matemática, tendo como fim das referidas aprendizagens a formalização axiomática e o apoio na lógica dos 
conteúdos ensinados" (op. cit., p. 14), manifestação que deve ser compreendida no contexto dessa publicação, em que a autora faz uma retrospectiva daquele período sem, no entanto, retirar o mérito de todo o trabalho então desenvolvido com a orientação do prof. Dienes.

Conforme Bürigo (1989), o GEEMPA enfatizou, desde o início,

os aspectos metodológicos da renovação do ensino. Nisso, foi beneficiário da experiência do movimento [da matemática moderna] em São Paulo, onde em 1969 e 1970 já se começava a reconhecer a insuficiência das reformulações de abordagem de conteúdo" [...], o que teria justificado, segundo Bürigo, a vinda de Dienes ao Brasil em 1971. Salienta, ainda, Bürigo que na origem do GEEMPA estava [...]"o trabalho dirigido ao ensino primário, onde as reformulações metodológicas sempre foram mais enfatizadas (p. 140).

\section{As classes-piloto: falando da experiência realizada}

A trajetória do GEEMPA apresenta inúmeras ações envolvendo professores, não só de Porto Alegre, e tem um papel de destaque na formação desses profissionais, tendo realizado uma série de encontros, seminários, palestras, reuniões de estudo, entre outras atividades. Bürigo (1989) considera que, sem ter rompido com a proposta da matemática moderna, "o GEEMPA seguiu um caminho que se distanciava da origem do movimento, conservando dele o que era um elemento central da proposta de Dienes: a ênfase nos aspectos estruturais envolvidos nos diferentes tópicos" (p. 140).

Um destaque, entre as inúmeras atividades promovidas pelo Grupo, pode ser feito às classes experimentais, ou classes-piloto, desenvolvidas em 1972, em escolas de Porto Alegre. O GEEMPA organizou as classes-piloto "para realizar uma experiência ainda mais avançada de renovação do ensinoaprendizagem no 1.ำ grau", conforme registra um dos documentos arquivados na sede do $\mathrm{Grupo}^{3}$. A experiência foi realizada com as oito séries do $1 .^{\circ} \mathrm{grau}$, assim denominadas na época, e baseava-se nas seis etapas do processo de aprendizagem da matemática de Dienes, identificadas pela professora Esther como: jogo livre, jogos estruturados por regras, comparação dos jogos, representação gráfica dessa comparação, invenção de uma linguagem e axiomatização. No livro em que o autor caracteriza tais etapas, há, segundo a professora Esther, "permanentemente a idéia de uma aprendizagem ao redor da ação sobre os objetos e com isto ele dava um passo em direção a um quadro

3 No acervo do GEEMPA, em sua sede em Porto Alegre, há inúmeros documentos que, no momento, se encontram em processo de organização, contando com os serviços de um profissional da área de arquivologia. 
teórico diferente do behaviorismo" (2005, p. 15), ao referir-se à introdução que o autor faz em seu livro, no capítulo em que trata da descrição das etapas:

Que é compreender? Que é aprender? Devemos confessar que não temos ainda resposta cientificamente satisfatória para estas duas perguntas. Se, por um lado, é verdade que ninguém pode atualmente duvidar de que a relação estímulo-resposta conduz a um adestramento que, tanto no plano da compreensão como no da aprendizagem posterior, representa, na maioria das vezes, bloqueamentos, falta, por outro lado, demonstrar quais são os elementos constitutivos do processo de aprendizagem, digno desse nome (DIENES, 1972, p. 1).

Tais considerações em nada desmerecem ou desqualificam a experiência realizada, há mais de 30 anos, com as classes experimentais. Foi uma experiência muito bem-sucedida, o que se pode concluir pelos depoimentos de professoras que atuaram diretamente com os alunos em tais classes e participaram da organização e preparação dos materiais utilizados nelas. A própria professora Esther, considerando os equívocos teóricos que poderiam justificar "a falha dos resultados de aprendizagens relativamente às proposições de Dienes, assim como relativamente à matemática moderna", considera que houve muitos problemas "na generalização de bons resultados nos sistemas de ensino, se comparados com o que se passou nas classes experimentais" (GROSSI, 2005, p.15-16, grifo nosso).

A presença do professor Zoltan Dienes em Porto Alegre, em 1972, é que motivou a organização de tal experiência com classes-piloto, experiência essa alinhada com a preocupação "de que, para renovar o ensino-aprendizagem da matemática são necessárias duas mudanças básicas (mudança de conteúdo e mudança de metodologia)", conforme referido em um dos documentos pesquisados nos arquivos do GEEMPA. Foram oito classes selecionadas, entre diferentes Estabelecimentos de Ensino, sete deles em Porto Alegre e um em Novo Hamburgo, cidade próxima da capital. A escolha deu-se por relação direta à capacitação dos professores, que atuavam nessas escolas, dentro dos quadros do GEEMPA. Em tais classes, conforme o documento pesquisado, "foi posta em prática uma metodologia com atividades diversificadas, a partir de um ambiente rico de situações de aprendizagem", seguindo as etapas do processo de aprendizagem do prof. Dienes.

Uma das professoras das classes escolhidas comenta a preparação e o acompanhamento do trabalho desenvolvido:

O trabalho era organizado assim: nós recebíamos orientação da Esther, em grupos, e aplicávamos as atividades, os jogos, todo o material era elaborado, estudado e tínhamos, uma vez por semana, uma colega que fazia uma espécie 
de supervisão, assistia às aulas nas classes-piloto e algumas vezes também interagia com os professores e com os alunos. Depois, nas reuniões seguintes, avaliávamos o trabalho do professor, o trabalho das crianças, a metodologia. Eu considero um trabalho de muita responsabilidade. Na época, era. Acho que nos empenhávamos para fazer o melhor, tínhamos desejo de crescer, de fazer um bom trabalho e, sobretudo, envolver as crianças, que, acho, foi algo que realmente se conseguiu (Marlene de Oliveira Leite, depoimento oral).

Em reuniões semanais, as professoras faziam o planejamento, confeccionavam os materiais e realizavam estudos teóricos, sempre com a orientação da professora Esther Grossi. Essa preparação toda fortalecia muito 0 grupo, ao contrário do que ocorria com as demais professoras, que não se envolviam nesses estudos, conforme se observa no depoimento de outra professora:

Uma das coisas que atrapalhou muito e criou um falso conceito da matemática moderna foi aquele professor mais acomodado, que não queria se empenhar, mas queria usar o jogo livre, que eles entendiam que era apenas deixar as crianças brincarem livremente, sem intervenções, sem observações e ficavam corrigindo trabalhos, fazendo outras coisas. Em seguida queriam aplicar as folhas de exercícios, mas, logicamente, as crianças não estavam preparadas, não tinham sido trabalhadas (Eva Medeiros Cavasotto, depoimento oral).

A professora Marlene, em seu depoimento, destaca a ênfase do trabalho realizado muito mais no aspecto metodológico do que, propriamente, no conteúdo:

Talvez os conteúdos não fossem os mais adequados, mas a dinâmica do trabalho e a elaboração de conceitos acontecia mesmo. Para mim, o que ficou claro foi que o aluno só aprende quando consegue vivenciar e trocar. No momento em que o aluno consegue vivenciar uma situação e trocar com os colegas, ele tem condições de realmente aprender. Se o conteúdo não era 0 mais adequado, não sei, mas a didática sim. Até hoje eu não saberia entrar em uma sala de aula e trabalhar diferente. Foi tão interessante que depois conseguimos transpor essa dinâmica para área de linguagem e surgiram trabalhos muito bons (depoimento oral).

Num dos documentos arquivados na sede do GEEMPA, já citado, intitulado "Visão por uma série de etapas, a organização e a orientação das classes-piloto. A primeira etapa, que trata da motivação, contém a referência à estada do professor Dienes em Porto Alegre, no mês de agosto de 1972.

Numa das etapas seguintes, encontra-se a identificação das classes escolhidas, com o nome da escola, a série, a professora e o número de alunos. 
Fato curioso é encontrar uma das escolas situadas fora de Porto Alegre que, provavelmente, deva se justificar pelo fato da professora ser uma das capacitadas dentro dos quadros do GEEMPA, conforme se pode inferir pela referência feita, no documento, ao grupo de professoras escolhidas. As finalidades e as idéias-fonte do trabalho nas classes-piloto constituem as etapas seguintes descritas no documento, em que estão registradas as bases inspiradoras do trabalho, que são: "a motivação depende da liberdade" e "a abstração é obtida a partir de situações concretas amplamente diversificadas".

Seguem outras etapas, em que estão descritas a metodologia de trabalho nas classes e a constituição da equipe de assessoramento, que acompanha o trabalho do regente da classe, com quem se reúne semanalmente, fazendo relatório das atividades realizadas e o planejamento da próxima semana, momentos que são descritos como riquíssimos em troca de experiências, em apoio mútuo e aprofundamento.

No documento, há ainda a descrição dos conteúdos de cada série, a referência à integração com outras disciplinas, à ficha de acompanhamento, à reação dos pais e à avaliação.

O documento contém, como anexo, um modelo de seqüência das atividades conforme foram desenvolvidas por uma das professoras, além da ficha de observação, que é preenchida semanalmente por cada classe.

Esse documento, além de outros materiais disponíveis no acervo do GEEMPA, constituídos como fonte para a pesquisa, passará pelos processos de análise e interpretação, a partir de hipóteses sobre os vestígios por ele deixados, buscando dar consistência ao objeto histórico em construção. Conforme Beatriz Fischer (2005), "o ato de decifrar a História é alicerçado justamente na reconstituição desses fragmentos aparentemente dispersos, que aos pesquisadores cabe tentar melhor compreender" (p. 23), considerando a riqueza dos dados neles contidos, a partir de uma metodologia e fundamentação teórica consistentes, que procuro apresentar a seguir.

\section{Considerações teórico-metodológicas}

Na tentativa de contribuir com a escrita da história dessa época, escolho a alternativa de pensar a História da Educação Matemática como especialização da História da Educação, conforme aponta Valente (2005a).

Nesse sentido, os documentos encontrados no acervo do GEEMPA, além das pessoas envolvidas na experiência das classes-piloto, serão as nossas fontes. A análise dos documentos, bem como dos depoimentos recolhidos, poderá ajudar a compreender de que forma se deu a apropriação das idéias de renovação do ensino da Matemática, à época do MMM, promovidas por esse grupo de professo- 
ras, engajadas na proposta de trabalho do GEEMPA. Essa análise exige "ir além daquilo que é dito, ver além daquilo que é mostrado", tal qual um detetive, conforme aponta Pesavento (2005, p. 64), como regra de ação ao historiador. Além disso, a autora destaca ser preciso, na recolha dos registros do passado, realizar com eles um trabalho de construção capaz de produzir sentido. E revela: "montar, combinar, compor, cruzar, revelar o detalhe, dar relevância ao secundánio, eis o segredo de um método do qual a Histónia se vale, para atingir os sentidos partilhados pelos homens de um outro tempo" (op. cit., p. 65).

Também destaca Certeau (1982), nessa mesma direção: "em história, tudo começa com o gesto de separar, de reunir, de transformar em "documentos" certos objetos distribuídos de outra maneira. Esta nova distribuição cultural é o primeiro trabalho" (p. 81, grifos do autor), o que consiste, na realidade, em produzir tais documentos, ao recopiá-los ou transcrevê-los para um outro lugar. Além disso, trata-se de não apenas dar voz a um silêncio, mas "transformar alguma coisa, que tinha sua posição e seu papel, em alguma outra coisa que funciona diferentemente" (op. cit., p. 83).

Nesse estudo, será preciso, também, considerar o contexto em que se realizou a experiência das classes experimentais, pois, como coloca Certeau (1982), toda pesquisa histórica "se articula com um lugar de produção socioeconômico, político e social" (p. 66). Isto diz respeito, especialmente, ao Movimento da Matemática Moderna, que ainda estava em desenvolvimento no país, na época, e que está no foco da investigação que realizo.

Ainda, nas entrevistas feitas, tratando de ouvir o que o professor tem a dizer, é preciso "respeitar e tratar rigorosamente os dados que o professor introduz nas narrativas" (GOODSON, 1995, p. 71), dada a relevância que tais dados têm para a compreensão das práticas postas em ação na época, ao mesmo tempo em que contribuem, conforme aponta Beatriz Fischer (2005) "para novas formas de análise e compreensão da realidade atual", considerando a riqueza dos dados "submersos ao longo dos anos" (p. 23).

\section{Resultados preliminares}

Estando o estudo em desenvolvimento, ainda há um caminho longo a percorrer para que se apontem resultados consistentes, sustentados pela investigação que realizo. Até o momento, porém, pelos depoimentos das professoras, pode-se verificar que a experiência organizada pelo GEEMPA, de desenvolvimento e assessoria às classes-piloto, representou uma importante contribuição, tanto na formação docente como na dos alunos. Foi um trabalho levado com seriedade, feito com muita reflexão e discussão entre todos os integrantes, conforme está manifestado nos depoimentos colhidos. 
O tratamento a ser dado ao material disponível nos arquivos do Grupo de Estudos, da mesma forma que às entrevistas, ainda demanda tempo para que se possa afirmar sobre a contribuição de tal experiência à história da Educação Matemática, que se persegue. O que se sabe, no entanto, é que para a análise do Movimento da Matemática Moderna na região de Porto Alegre não se pode prescindir dos trabalhos do GEEMPA, realizados na época. E um deles, entre outros tantos, é a experiência aqui trazida, das classes experimentais em séries do 1.ํo grau.

De toda forma, pelo confronto que ainda é preciso fazer entre os depoimentos e os documentos a que tivemos acesso, será possível buscar as respostas que intentamos encontrar a perguntas como: de que forma cada escola acolhia a experiência, realizada numa de suas classes? Como era a relação com as demais turmas da mesma série, na escola da classe-piloto? Foi possível socializar os resultados da experiência com outras turmas e outras escolas de Porto Alegre ou, mesmo, do Estado? Como é que se desenvolveu uma experiência tão positiva numa análise preliminar - quando o Movimento da Matemática Moderna já dava sinais de fracasso mundialmente?

\section{Considerações finais}

Situada num conjunto de outras pesquisas acerca do Movimento da Matemática Moderna (MMM), em desenvolvimento pelo GHEMAT ${ }^{4}$, esta investigação trata de parte das ações que se desenvolveram na época do MMM e que pretende contribuir com o estudo acerca da sua recepção nas práticas pedagógicas dos professores do ensino dessa disciplina. Assim, a análise dos documentos contidos nos arquivos do GEEMPA e dos depoimentos das professoras acerca da experiência com as classes-piloto, mesmo que em fase preliminar, sinalizam uma contribuição importante ao estudo histórico da matemática escolar, em prática especialmente ao tempo desse movimento de renovação do ensino da matemática.

Ainda são escassas as pesquisas acerca do MMM, no Brasil, que aprofundem os estudos sobre as conseqüências do Movimento, especialmente quando à sua recepção nas práticas dos professores de matemática, conforme levantamentos iniciais realizados pelo GHEMAT. O desafio de preencher essa lacuna histórica está sendo buscado por este

\footnotetext{
4 A Matemática Moderna nas escolas do Brasil é um projeto de pesquisa em elaboração pelo GHEMAT - Grupo de Pesquisa de História da Educação Matemática, vinculado à PUC-SP, e que envolve pesquisadores de várias cidades brasileiras.
} 
Grupo, cuja proposta de pesquisa sobre a recepção do MMM no Brasil aponta para a necessidade de escrita de uma história da educação matemática comparativa, dado que o movimento irradiou-se pelo país por diferentes grupos de estudos, que se tornaram referência do ideário do Movimento o que, ao que tudo indica, resultou em formas diversas de apropriação da Matemática Moderna no país (VALENTE, 2005b). Entre estes grupos, encontra-se o GEEMPA, de Porto Alegre, responsável pela orientação das classes-piloto tratadas neste texto.

Estas são considerações finais para o texto, dado que ele exige um ponto final. Mas são preliminares, ainda, para a pesquisa que venho realizando. Com a possibilidade de encontros com outras professoras envolvidas com os trabalhos do GEEMPA, bem como de acesso ao acervo do Grupo, sigo com o desafio de contribuir com a escrita de uma parte da história da educação matemática desse canto do país.

\section{Referências}

BÜRIGO, Elizabete Zardo. Movimento da matemática moderna no Brasil: estudo da ação e do pensamento de educadores matemáticos nos anos 60. 1989. 208 f. Dissertação (Mestrado em Educação) - Faculdade de Educação, Universidade Federal do Rio Grande do Sul, Porto Alegre. 1989.

CERTEAU, Michel de. A escrita da história. Tradução de Maria de Lourdes Menezes. Rio de Janeiro,RJ: Forense Universitária, 1982.

DIENES, Z. P. As seis etapas do processo de aprendizagem em matemática.

Tradução de Maria Pio de Macedo Chartier e René François Joseph Chartier. São Paulo,SP: Helder, 1972.

FISCHER, Beatriz T. Daudt. Professoras: histórias e discursos de um passado presente. Pelotas: Seiva, 2005.

GOODSON, I. Darvoz ao professor: as histórias de vida dos professores e o seu desenvolvimento profissional. IN: NÓVOA, A. (Org.) Vida de professores. Porto, Portugal: Porto, 1995. p. 63-78.

GROSSI, Esther Pillar. O GEEMPA, uma vivíssima ONG. Em Aberto. Brasília, v. 14, n.62, p. 97-99, abr./jun. 1994.

. Uma arqueologia dos saberes do Geempa. Revista GEEMPA (35 anos). Porto Alegre, n. 10, p. 11-39, set. 2005. 
PESAVENTO, Sandra Jatahy. História \& História Cultural. 2.ed. Belo Horizonte: Autêntica, 2005.

ROCHA, Ana Luiza Carvalho da. GEEMPA 30 anos. Publicação Especial. Porto Alegre: [s.n.], 2000.

VALENTE, Wagner Rodrigues. A matemática na escola: um tema para a história da educação. In: MOREIRA, Darlinda; MATOS, José Manuel. (Orgs.). História do Ensino da Matemática em Portugal. Lisboa: Sociedade Portuguesa de Ciências da Educação, 2005a. p. 21-32.

A Matemática Modema nas escolas do Brasil: um tema para estudos históricos comparativos. In: CONGRESSO IBERO-AMERICANO DE EDUCAÇÃO MATEMÁTICA, 5., 2005. Actas... Porto, Portugal: Faculdade de Ciências da Universidade do Porto, 2005b. CD-ROM.

Recebido: 04 de dezembro de 2005 Aprovado: 28 de março de 2006. 